\title{
Analysis on the Spreading Path on Line of Folk Culture in the Internet Era-Based on the Study of Folk Culture in Jilin Province
}

\author{
Yue Wang \\ College of Business Administration, Jilin Engineering Normal University, Changchun, China \\ 51386781@qq.com
}

Keywords: Folk culture; Spreading path; On line; Internet Era

\begin{abstract}
Publication is always the very important method for preserving and spreading the folk culture. In the Internet age, spreading on line gives more opened and polybasic spreading methods to the folk culture. According to the relative research of folk culture in Jilin Province, there are four spreading paths on line of folk culture to be studied: using the social media, like Wechat and Micro-blog; deep cooperating with tourism website; exploring the materials from online games and digital animations; applying the virtual reality technology.
\end{abstract}

\section{Introduction}

By the promoting of strategy of powerful cultural country, the cultural industry in our country is rapidly developed. Publication is regarded as the very important media and method of cultural accumulation and cultural transmission. The material choosing, the content processing and marketing and so on, are leading and promoting development of human culture. Folk culture is not only a part of culture soft power, but also the important target of development for choosing materials of publication. In a time when information technology improves rapidly, the folk culture loses much visible material carrier and invisible skills by the technological civilization. But from another aspect, the technological civilization also gives the new age meaning and more development space for the folk culture. In the Internet age, the publication of folk culture is not only limited by the traditional ways of book publishing, but also integrating more creative ideas and skill element, which can make the polybasic spreading effect.

\section{Effect of Spreading on Line to the Folk Culture Spreading}

Folk culture is the life achievement of a country, a nation and an area. It has the typically regional features [1]. In the background of globalization, folk culture needs to keep the features of the regional culture, and break through the regional limitation. It should strengthen the protection of the folk culture, and focus the creation of the folk culture [2]. For the spreading of folk culture, there are many unique advantages of spreading on line from the perspectives of effectiveness of spreading, form of spreading, scope of spreading and channel of spreading.

Breaking the Restrictions of Time and Space -- Improving the Effectiveness of Spreading the Folk Culture. The folk culture, which possesses the special local characteristics, no matter material culture or spiritual culture, is spread in the specific region to the specific people, which is restricted by the region [3]. From producing to spreading, from content to form, the product spreading on line takes the virtually digital information as the basis, and does not rely on the traditional way of packaging and logistics. So that spreading on line can break the restrictions of time and space and spread the information around the world by the effective speed. Folk culture, a kind of local civilization, a part the world civilization, is spread on line around the world, which is the responsibility and mission of us [4].

Multimedia Elements -- Enriching the Ways of Representing the Content of Folk Culture. By the variety of ways and rich content, folk culture shows the special charm in the history of publish culture. For a long time, the publishing of folk culture takes the books and periodicals as the carriers. 
Static text of paper printing and pictures are the important function for the promotion and introduction of folk culture. In the new media age, this way of spreading cannot satisfy the readers' diversified and individual necessities about the folk culture. But, spreading on line can synthetically apply the pictures, text, sounds and video to make the product, which can unify the cultural content and technological innovation, improve the artistic expressive force of folk culture and let the folk culture shine with the extraordinary splendor in the spreading on line age.

Mobile Networking -- Expanding the Ways of Information of Folk Culture Communicating. As for the folk culture spreading, the openness and variety of spreading ways influence the deepness and range of spreading to some extent. By the mobile network increasingly, mobilized and fragmentized reading are more and more popular [5]. The new spreading way not only provides more opportunities of accessing the information, but also makes the possibility that let the information shared in the specific crowd. The mobile phone is the greatest potential type in the spreading industry. It can contain many media ways at the same time, like e-book, e-journal, music, video, which provides more flexible choices for spreading the folk culture.

Interactive Gameplay -- Providing the Enjoyment of the Folk Culture Knowledge. For the mass culture and pop culture, folk culture has the limited influence and spreaded scope [6]. Some local folk culture cannot be accepted by the outlander because of its hardness of understanding. The previous spreading forms of folk culture are unitary. Some of them are presented by the textbooks, which is very hard to motivate the readers' passion. Spreading on line is strongly interactive. The publishing and update is not related to only one editor or writer any more, but many people can be involved to create. Every participant can steep himself into the specific atmosphere of folk culture to feel and study. The new spreading way not only increases the enjoyment of folk culture, but also improves the attention of the folk culture.

\section{Spreading Path on Line of Folk Culture}

The spreading on line of folk culture is the effective measure to integrate the outstanding resources of folk culture and promote the development of ethnic culture industry. In the process of spreading on line, we must hold the relationship between content and form, culture and technology. We also should excavate the cultural resources with local features, combine the advantages of traditional culture product with the advantages of technology of spreading on line. We need to choose the most suitable path and way of spreading on line to enchant the value of folk culture (Fig. 1).

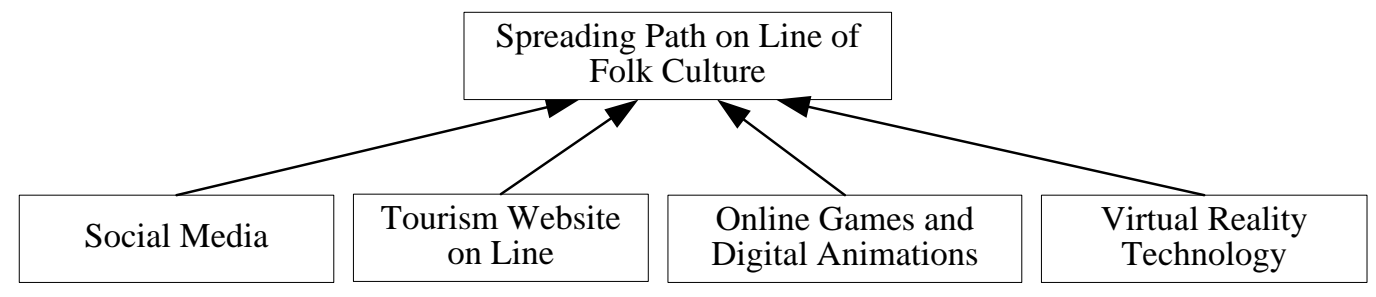

Figure 1. Spreading path on line of folk culture

Using the Social Media, Like Wechat and Micro-blog. In the new media age, everyone can use the social media, like Wechat and Micro-blog, to be a "we media". Then you can publish, repost, comment and share. Folk culture has the features of regionalism [7]. Because of the similar thought and behavior, the region or the nation can form a social circle easily to make voice in the network environment. The spreading pattern of information sharing, which is based on the user relationship, is the trend of the media revolution in the Internet age, and the orient of the exploration of spreading on line in the background of mobile reading [8]. Spreading of micro-blog and wechat relies on the micro-content. Micro-content is relative to the integrity and systematic of the traditional published content. Any piece of text, any picture, any audio and any video can be the main content of spreading. 
The fragmented spreading pattern is more flexible, rapid and more pointed. It can combine the grouping of the spreading subject with the regionalism of the folk culture perfectly.

There are many abundant and brilliant resources of folk culture in Jilin Province. Some of them are living in the really life, which is spread by the way of teaching orally. It is a very big challenge for the edited work to collect the resources and publish them. This needs the editors' acuminous vision and strict attitude. From the perspective of market, the readers of the books about folk are limited. Except the academic research, public need the more and more individualized and lived folk information. So, the inheritors and publishers in Jilin province should pay attention to the individualized requirement of users to develop sufficiently the efficiency of the spreading by social media, like Micro-blog and Wechat, and to publish the related content by applying the circle of friends and public number. For example, the micro-blog of Tonghua Guandong folk village interacts on line and off line to introduce the activities of folk culture and promote information of the decoration, food and drink. The interaction in the micro-blog is effective.

Deep Collaboration with Tourism Website on Line. Tourism culture is a part of culture industry resources. It is very meaningful to promote the local economic construction and culture development. As the improvement of people's living standard, more and more people choose to travel in their holidays. Folk custom tour is a popular type of tours recently. To increase the travel quality and decrease the travel risk, many people buy the books about travel guide or travel strategy before travelling. These books can introduce the local travel information comprehensively. But because of the long publication periods, the content of some books is divorced to the reality, which leads to the late or different information. Therefore, many people tend to catch the information from the Internet to know the local related information. Right now, the development momentum of the tourism website is stronger and stronger. It not only provides the reservations of the tickets, transportation, administration and diet, but also the evaluation and comments of the scenic spot and the quality of service. This is a new type of travel consumption pattern.

Table 1 Types and main contents of folk tourist attractions in Jilin Province

\begin{tabular}{|c|c|c|}
\hline Class & Subclass & Contents \\
\hline \multirow{3}{*}{$\begin{array}{l}\text { Material } \\
\text { folklore }\end{array}$} & Folk of diets & $\begin{array}{l}\text { Stewed Pork with Vermicelli, Hot pot, Dumplings, Sachima, Rice cake, } \\
\text { Hot pot with dog meat, Salami, Roasted Whole Lamb, Fried rice, } \\
\text { Chilled noodles and Pickles etc.. }\end{array}$ \\
\hline & $\begin{array}{l}\text { Residential } \\
\text { custom }\end{array}$ & Brick bed warmed by fire underneath, Mongolian yurts etc.. \\
\hline & Folk specialties & $\begin{array}{l}\text { Ginseng, mink, pilose antler, Songhua inkstone, Ann Green stone } \\
\text { carving, Rhododendron root carving, bark paintings, Dongfeng farmer } \\
\text { paintings and Hatha etc.. }\end{array}$ \\
\hline \multirow{3}{*}{$\begin{array}{l}\text { Social } \\
\text { folklore }\end{array}$} & Festival custom & $\begin{array}{l}\text { Naadam Fair, Sixty Feast, Festival for the Elderly, Banjin Festival, } \\
\text { Ghost Festival and Temple Fair in North Hill etc.. }\end{array}$ \\
\hline & Marriage folk & $\begin{array}{l}\text { Present gifts to fiancee's family at time of betrothal, delivery of } \\
\text { betrothal gifts to the bride's family, wedding ceremony, engagement, } \\
\text { betrothal gifts, accompany bride to bridegroom's family on wedding } \\
\text { day, Grab marriage and Betrothal marriage etc.. }\end{array}$ \\
\hline & Folk belief & Shamanism, Buddhism, Christianity, Catholicism, Islam \\
\hline \multirow{2}{*}{$\begin{array}{l}\text { Spiritual } \\
\text { folklore }\end{array}$} & Folk music & $\begin{array}{l}\text { Song-and-Dance Duet, Vocal Music, Dance Music, Instrumental Music, } \\
\text { Eclogue and Folk Song etc.. }\end{array}$ \\
\hline & Folk dance & $\begin{array}{l}\text { Northeast Yangko, Sword Dance, Long-drum Dance, Dragon Drum } \\
\text { Dance, Agricultural Dance and Mongolian Dance etc.. }\end{array}$ \\
\hline
\end{tabular}

There are abundant and colorful travel resources in Jilin province. There are rich folk culture resources in Jilin province (in Table 1). These folk resources are the representatives of tourism culture in Jilin province, and also are the specific reflects of Northeast culture, Shamanistic culture, Mongolian culture, Korean culture, Changbai Mountain culture and ecological culture in Jilin 
province. The natural landscape and the landscape combine with each other. The most representative travel culture includes the Guandong culture, the shaman culture, Mongolian culture, Korean ethnic culture, Changbai Mountain culture, ruin culture and eco-culture and so on [9]. In the travel culture symbols, except the scenic spot, there is a very tight relationship with folk custom. So, the promotion of folk culture can be more successful by the popular of folk culture travel. For example, tourists reserve the travel on line to Changbaishan area in the holiday of Dragon Boat Festival. After the indent finishing, the website can send a message to tourists to introduce the local custom about the culture of Dragon Boat Festival. In the Dragon Boat Festival, we can sacrifice Quyuan, hang mugwort and tie the five colored ropes. Dragon Boat Festival is hottest in the folk sports in the traditional festivals of Korea. In this day, people can do many folk sports, like playing on the swings, jump diving board and wrestling. The most famous sport is the swing, which can let the tourists integrate in to the local culture and life. Besides that, there are some taboos about folk culture in some minority area, which needs the tourism website to deliver the information by a suitable way.

Exploring the Materials from Online Games and Digital Animations. In the online games market, the online game which contains the Chinese traditional culture is so popular that people praise them highly and like them very much. There are some specific advantages of online games in the aspect of inheriting the culture, like the beautiful picture, funny stories and interesting interactions. All of them can let the players feel and touch the culture potentially. The first folk online game in China, Q Qun Xian Zhuan Online, is a $\mathrm{Q}$ version online game which is based on the classic folk stories. It implants more than ten folk tales in ancient China, which provide a wonderful legend of folk history to the players. So folk culture can be alive under the packaging and illation of the games. The digital animations, as a new creative industry, use the elements of color, line and voice to present the proper symbol of folk culture. For example, in the excellent Japanese animations, cherry, kimono, backswood and shrine are the typical clothes, props and situation, which are deliver the local culture effectively. It gives the important directions to the application of digital animations in the folk culture elements in China.

As the culture province and science and education province, there are some resources advantages and talents advantages in the aspect of exploiting the online games and digital animations in Jilin Province. At present, there is a tense competition in the online games industry. The most important way of culture development strategy in Jilin province is to create the locally competitive products. Combining the traditional folk culture and the new media technology, not only can increase the expressive force of art in the folk culture spreading, but also drive the development of local culture industry, and then accelerate the win-win efficiency. For example, since the Jilin original cartoon game industrial park has been set up, they believe in the spiritual flag of advance and enrich the national culture and insist on the original cartoon, to create more influenced excellent works. Certainly, the combination of online games, digital animations and folk culture not only simply implants some props and scenes in the games, but also excavates the spiritual connotation of the Chinese excellent traditional culture, which can make the culture value prominent by the creative way.

Applying the Virtual Reality Technology. In recent years, the perfection of three-dimensional animation and virtual reality technology provide the technical support for promoting the folk culture. Virtual reality is the new way that people can operate and interact the complicated data visually by the computer. The users can experience stimulate as real in the virtual three-dimensional space. By using the virtual reality technology, the construction, clothes, festivals, customs, craft and etiquette in the folk culture can be restored and preserved vividly and realistically, which can become the never once lost online culture resource. Especially for the tourist attraction and diverse culture, virtual reality can propaganda them effectively [10]. For example, Changbai Mountain International Tourism Resort makes a digital content about the origins of Korea nationality. By collecting the local resource, it represents the scenes of life of Korea nationality in the ways of full disk-image, which can let the audience feel the temporal culture customs across the time and space. 
There are many historical and cultural sites and culture heritage in Jilin province. Today's life is full of virtual travel. Applying the advanced virtual reality technology into the protection and promotion of historical culture heritage can give a new life to the history which cannot be reproduced and is forgotten by the human. Right now, many places put forward the virtual reality tourist project. By using the 720 degree three-dimensional live-action, tourists can travel around the scenic spot with going out of the door. The ways of online spreading basing the virtual reality technology not only save the resources, but also protect the environment. It is also pricelessly meaningful in expanding the influence of scenic spot, promoting the national folk culture and driving the economic development.

\section{Conclusion}

Folk culture is the important topic resources of spreading culture. Publishing is the dominant way to advertise and promote the folk culture. In the background of digitization, networking and globalization, the online construction of folk culture is the necessity of self-heritage and development. It is also the necessary method to promote the traditional culture "going outside". Leading the spreading of folk culture by spreading on line is conductive to excavate the different forms of developing folk culture resources. It is also conductive to transform the culture resource into the culture product, and then create the influenced cultural brand, which can inject the new life and energy for the development of local culture industry.

\section{Acknowledgements}

This work was financially supported by Social Science Foundation of Jilin Provincial Education Department and the Research and Development Project of Jilin Engineering Normal University.

\section{References}

[1] G.M. Foster: American Anthropologist, Vol. 55 (1953) No.2, p.159-173.

[2] B. Chang: Journal of the American Dietetic Association, Vol. 65 (1974) No.4, p.436-438.

[3] H. Bausinger: Zeitschrift Fur Volkskunde, Vol. 81 (1985) No.2, p.173-191.

[4] H. Fischer: 4th International Congress of the Soc-internationale-D-Ethnologie-Et-De-Folklore (Bergen, Norway, June 19-23, 1990). Vol. 87, p.93-106.

[5] T.J. Blank: Western Folklore, Vol. 72 (2013) No.2, p.105-130.

[6] M. Michel: Western Folklore, Vol. 74 (2015) No.2, p.201-215.

[7] G. De Meyer: Volkskunde, Vol. 106 (2005) No.1-2, p.3-+.

[8] S. Poole: Folklore, Vol. 126 (2015) No.3, p.362-363.

[9] Information on http://www.changbaishan.gov.cn/weball/main.aspx

[10]E.O. Ozunel: Milli Folklore, Vol. 102 (2014), p.5-16. 